\title{
[ 23r]
}

\section{VIII.}

$$
G \text { e } e^{n} b \text { e in e } r k u n g \text {. }
$$

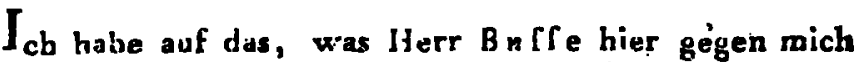
vorguhrarht har, nur lolgendes zn et wiedern.

Frlllich tuiffi der Vurwurf einer Verwechfelung von. Anzeige mit Anfrage mich nicht. Denn Hernn Buffe's Anzeige enthali lo woinl die Anfrace, ob der darin ervilinte Silz cin Stein des Anftofses geworden fey, dis die Anzeige, dals Herr Bulle zum Bewreile deflatuen die Natusuhioolophie in lieguilition goletzt habe. Ich balse auch jene Anfiage nicht beantworten wollen. Condern nur Bemeikunsen darüleer geindcht, worin ich K a fl ner's Beilpi.t vor mir hatte. ${ }^{\circ}$ ) Zweid tens rechnet es mir Hr. Bu c $\mathrm{Cl}$ zur Unhüfiichkeit oder Unartigkeit:an, dals ich die Beweife eines leichten Satzes unitgetheilt hahe, da es einer [olchen Nittheilung niche bedürfe. Diefe thittheilung war aber eben nöthig, um zu zeigen, dals der Satz nicht von der Art ley, dals Herr $B$ u If $e$ einem beriihmten Viathematiker zutrauen konnte, don Bew eis sicht augenblicklich ohne Hülfe cier Naturplitulinphie zil finden.

Was das iilrign anlingt, und befonders, ob ich nicht der Fordorung Herrn Bufle's in Anfehung des Problems aus der Lelıre von den anziehenden Kräten dadurch, dals ich nicht eine, fundern zwai Formeln für die Gefehwindigkeit diesfeits und jenfeits. des kiit: telpunkts der Anzethung, und zwar mit Hülle der newöhnlichen Theurie der entgegen geferzten Grölipn gegeben, vollkommen Genin „e geleiftet halse, überlafle ich den Lefern zur Beurtheilunig und Enifcheidung.

$$
\text { Mollweide. }
$$

*) II. C. unter andern deflen Geom. Abhandl., Samml. I, Ablaudl. 59. 


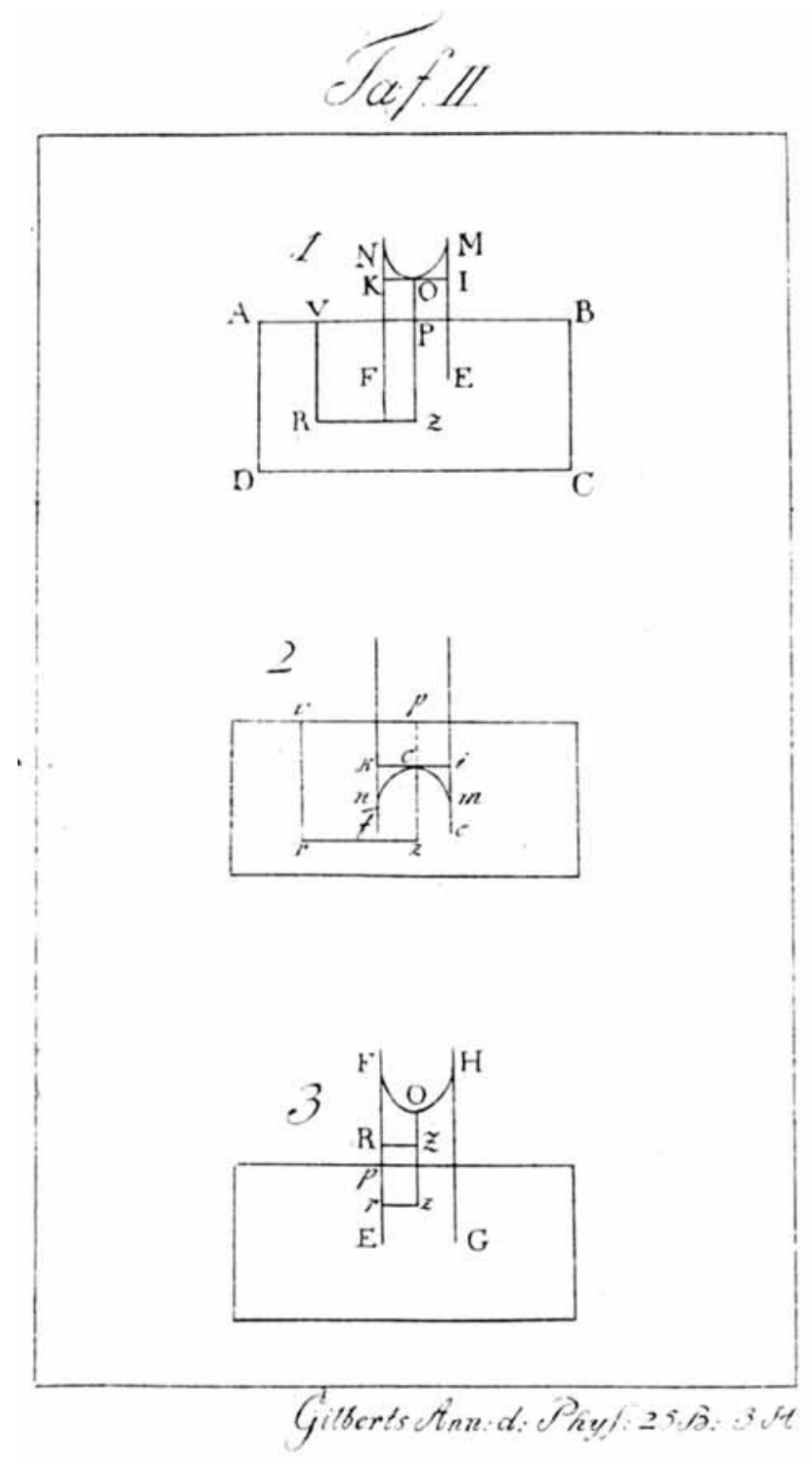

